\title{
Opportunities for Multi-Lingual Education in Nepal
}

Dr. Bidya Nath Koirala*

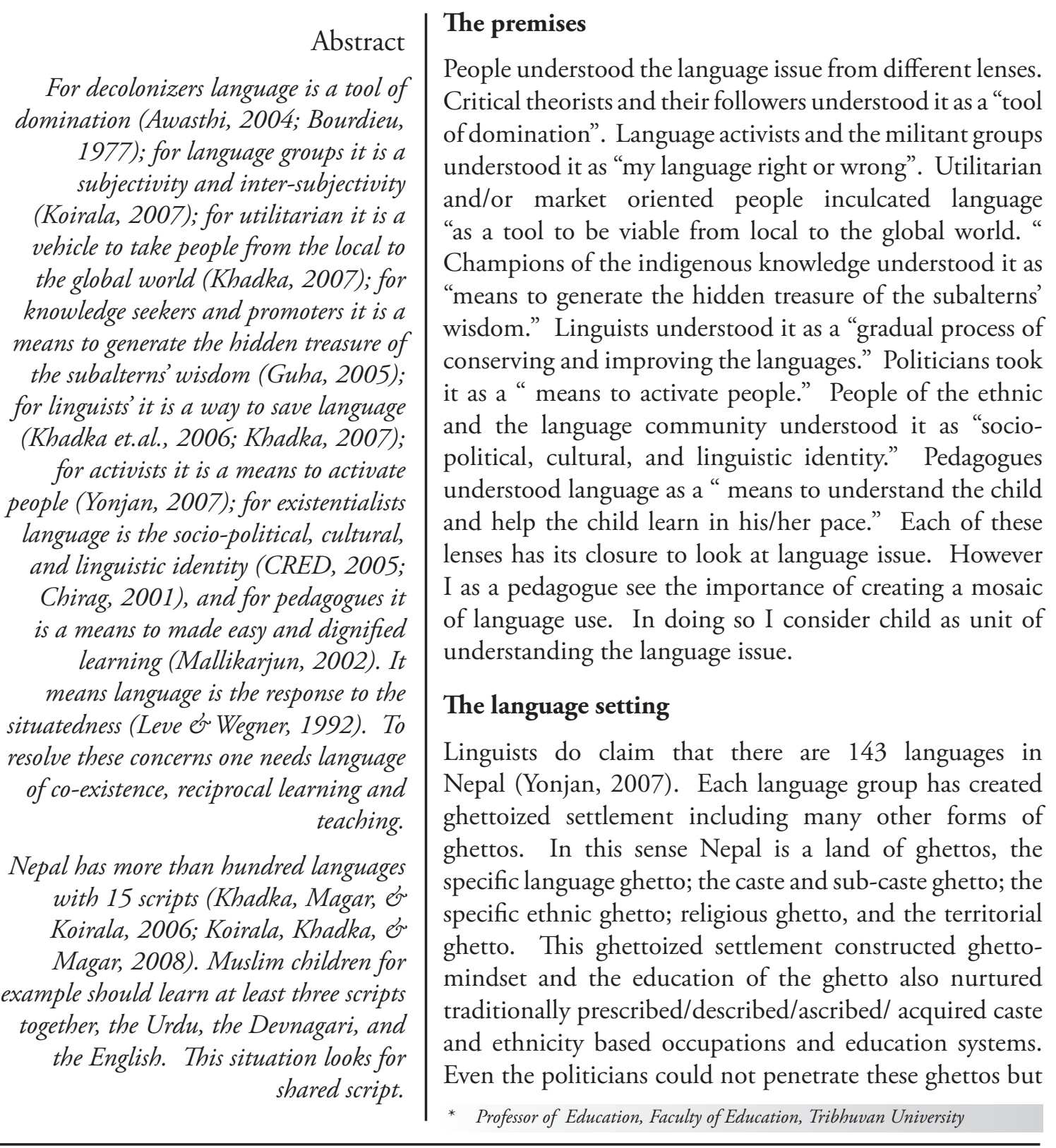

Journal of Education and Research Vol. 2, 2010 
Opportunities for Multi-Lingual Education in Nepal $\mid 31$

became a shareholder of them. Paradoxically, school on the other hand embraced students of different ghettoes. Consequently we have five types of classroom setting ${ }^{1}$ (CRED, 2005) in terms of students' language background and three types of teachers from teachers' inter-ghetto mobility point of view ${ }^{2}$. However the orientation of the formal education program, migration, communication, and exposure compelled teachers and students for boarder crossing in language issue. This boarder crossing demands inter-ghetto communication, the lingua franca no matter they are locally accepted, nationally imposed, and/or internationally imitated. The first force has emerged out of the necessity. For example Batar, Jhangad, and Tharu of Jhorahat, Morang created and used Dehati language as lingua franca at the local level. So did the Lepcha, Rai, and Limbu of Ilam who used Nepali as lingua franca. The second force has been the oppressive structural force of the state and its apparatus including teachers that advocated various language policies over the periods (National Language Policy Recommendation Commission, 2050 BS). This force did not and could not visualize what Darrida calls "difference and diffarance" (Powell, 2000) between teachers' and students' mother tongue and the multilingual settings of the Nepali classrooms. This I would call 'conceptual blindness' did not allow teachers, teacher educators, and administrators to look for 'boarder crossing' approach to language issue. It is where pedagogues could not think multilingual setting as an asset. Consequently this issue has remained as unsolved or differently solved. In other words, the country does not have a set of language setting in the classroom (CRED, 2005; Awasthi, 2004, CHIRAG, 2001). Each setting

1 One language setting, two language setting, three language setting, four language setting, and five language setting, and multi lingual setting.

2 My field experience of Bara, Banke, Baglung, Surkhet, and Sindhupalchok shows that there are teachers and students speaking the same language; teachers and students speaking different language but communicating in Nepali language; teachers learning students' language and communicating with students easily. has its specific characteristics. For example, in one school of Makawanpur district, the students were from Tamang and Chepang community. The teacher on the other hand was from Maithili speaking community. The teacher was teaching mathematics and science in Nepali language. Here Nepali had been the lingua franca between the Maithili speaking teacher, and Tamang as well as Chepang speaking students of a class. However the teacher was learning Tamang and Chepang language with the students. Because of his effort he was able to communicate with Chepang students in their language and at the same time he was trying to learn Tamang. This shows that there are teachers who are harnessing the strengths of multi-lingual setting and adjusting themselves.

My experience with the Pahari students of Badikhel of Lalitpur district and the research done in this area (Khadka, 2007) gives another scenario; the scenario that teachers put blame on students and students on teachers. More importantly Nepali speaking teachers believe that Pahari children know Nepali language. This belief of the teachers shows their hesitance to learn Pahari language. Here the language setting is not that matters but the attitude of the teachers to learn Pahari language and value it in the classroom.

The testimonies above show that planners, teachers, pedagogues, language activists, and linguists have ignored the child. In other words they have valued the language, culture, politics, and identity but have failed to value the child of different language groups simultaneously.

\section{The trend}

I could capture seven trends in school setting. One, we are composed of cosmic I of the ancestors; historical I of Hermeneutics; critical I of Karl Marx; humanist I of Sartre; and socioculturally negotiated I of the field. These "Is" have advanced described, prescribed, ascribed, and deconstructed identities as default of the 
32 Bidya Nath Koirala

multilingual groups. These identities again have perpetuated the ghettoized mindset even in the academic field. Because of this situation, inter identity dialogue has been limitedly encouraged rather ghettoized academia and linguists have been working. So they have presented Nepali as killer language and at the same time promoted "intermediary killer language" in different parts of the country. Here the question arises, how many "intermediary killer languages" we want for this country? Linguists and politicians may answer it easily but a pedagogue is always silent. By borrowing the language of Paulo Freire I thus claim that the academia including teachers have perpetuated "the culture of silence." So the activist of the particular language has been talking about his/her language. But the teacher has to deal with many languages in a classroom. The question to the teacher thus is how to help students of different language groups simultaneously.

Two, when the teachers go to take training on how to teach language, they are taught about a specific language, i.e. teaching English and teaching Nepali. Here the training organizers ignore the language groups of the classroom. So they do not bother to link the grammar of the Tharu, Maithili, Tamang, and Sherpa with the grammar of Nepali and/or English. This what I call "classroom language blindness" of the teacher and the trainer victimizes students. The linguists on the other hand have nurtured this process of victimization as well. Here I would argue that we are the flag holders of a language but the ignorers of the classroom setting and the teacher composition of the country.

Three, the language activist tries to treat all the languages one to one. From egalitarian point of view they are very right. At the same time they are opting for Language University/language college/language school/language learning center in different languages of the country. But this voice is not coming as it should come forward. And yet they are not thinking to develop language corner in each school if there are more than one language groups.
Four, linguists and language activists are producing books, magazines, and newspapers in different languages. But at the same time they are ignoring the fact that a student, a teacher, and a community elite also can write books in different languages simultaneously. This mothering approach of the linguists and the language activists may take half a century to reach at all the students of different language groups of Nepal.

Five, language activists have advocated for mother tongue teaching in one place and sent their children to English school on the other. Even their children communicate in third language, the language of the television, Internet, and radio. Linguists and the language activists at this point might have ignored the need of simultaneous/ early/middle/latter/late language immersion approach to teaching. Even the pedagogues and the teachers are not oriented in this issue.

Six, educational administrators and managers understood language as a subject. Teachers on the other have used language as medium of instruction. Linguists and language activists understood language as rights of the people to learn in their mother tongues. But we are not developing common consensus from a child's point of view. Here the question comes who has the right to decide language for a child. Is this the right of the child to choose the language that $s / h e$ likes? Is this of the parents to decide the language for the child? Is this of the local government/ proposed provincial government/national government to select a language for a child? Is this of the teachers to prescribe a particular language to the child? There are many actors and actions to raise many other questions related to the decision makers of the language choice. But how many of us discussed it? I think no one bothered to do so. In this sense could we label us as the "colonizers of the child?" This question applies to all of us no matter we are linguists, language activists, teachers, teacher trainers, teacher educators, pedagogues, politicians, education administrators and planners.

Seven, Nepali NGOs including indigenous organizations in collaboration with INGOs 
Opportunities for Multi-Lingual Education in Nepal $\mid 33$

introduced mother tongue literacy classes in different parts of the country. But these programs were not continued for number of reasons and one of them was the interest of the learners to learn the second language other than their first language (Khadka, 2006).

The assessment of the above trends explicitly shows that child of different language groups are not taken care simultaneously but fragmentarily. This fragmentary view of linguists and the language activists has done injustice to the child who studies in multilingual classroom setting. Here again child has not been the unit of analysis but language, culture, identity, and politics.

\section{The opportunity}

Robert Chambers once asked the question, whose reality counts, whose knowledge counts? Borrowing the same question a teacher and a pedagogue can ask the question to the linguists and language activists whose language should I use in the multilingual classrooms of Nepal. An aware student may ask the same question to the teacher, pedagogue, and the advocators of proposed provincial language of Nepal whose language I am supposed to learn in my multilingual classroom. This unanswered question can be answered through language coexistence approach to teaching. This approach believes that language learning is a fun, an identity, a means to compare the word/the grammar/the syntax of a child's first language with many other languages of the classroom, a way to involve students in research, and a means to ensure students' inclusion in the world of languages. This applies to all of us who aspire for learning more than one language. But how many of us are aware of it. How many teachers do compare Nepali language with English language? How many of us do the similar job with Bhojpuri, Nepali, and English language who teaches in the Southern parts of Nepal? This means we failed to link approach, method, and technique of learning/teaching of different languages even in the classroom. This applies to all the teachers of Nepal who deal with more than one language either through teaching or through dealing with the students of different language groups. At this point, I foresee the following opportunities for us who advocate for multilingual education and think around a student who has different mother tongue than the language of the books and the language of the teachers. Such opportunities with us are:

1. We can prepare teachers to learn students' mother tongue from the students and facilitate his/her language-learning process. Such teachers and pedagogues are around with us though few in numbers.

2. We have teachers and students who want to teach and learn different languages simultaneously as the people of Karnataka, India (Mallikarjun, 2002). They are also interested in learning different models of language immersion and submersion in early and late age of the students.

3. We have teacher educators and the pedagogues who are willing to develop multimodal teacher preparation program and language evaluation systems as in Hungary (Vicsi \& Vary, nd).

4. We have teachers, pedagogues, and linguists who are interested in language apprenticeship model of teaching in multilingual setting as in England (Jones et. al., 2005).

5. We have teachers/students/local elites who are interested in producing multilingual dictionary as Khadka et. al. (2006) developed at the national level.

6. We have energetic teachers, pedagogues, linguists, and curricula developers who want to produce multilingual materials including curricula and textbooks by following the approach of preparing materials for the schools of Barbados.

7. We have the people who want to give up the idea of thinking language from language, culture, politics, and identity perspective. Instead they are the ones who think language from child's point of view and help him/her 
34

learn others languages which s/he needs for survival at home, community, nation, and the globe.

8. We have the pedagogues and teachers who know how to prepare teachers to use students' cultural capital (Bourdieu, 1977) and help them learn each other's language simultaneously.

9. We have people who want to run language learning school/college/university/learning centres as the Sanskrit university though they lack financial resources

10. We have pedagogues, teachers, linguists who want to undertake language survey and macro as well as micro research in language issue.

11. We have IT advocators in classroom who are working for one laptop per child. These advocators have already started to develop multilingual laptop for the students of elementary grades.

\section{References}

Awasthi, L. D. (2004). Exploring monolingual school practices in multilingual Nepal. Unpublished PHD Thesis. Danish University of Education, Copenhagen, Denmark.

Bourdieu, P. (1977). The School as a conservative force: Scholastic and cultural Inequalities. Chicago: The University of Chicago Press. Translated by Richard Nice.

CHIRAG (2001). Bilingual education. Kathmandu: Author.

CRED (2005). Mother tongue intervention at primary level. Kathmandu: Author.

Jones, N., Barnes, A. \& Hunt, M. (Winter, 2005). Thinking through languages: A multilingual approach to primary school languages. In Language Learning Journal, 32, $63-67$.

Khadka, A., Chaudhary, T., Magar, K. J.,
Chaudhary, A. \& Pokhrel, R. (2006). Literacy in multilingual perspectives: Learning from Tharu, Tamang, Newar and Limbu language communities in Nepal. Kathmandu: World Education/ UNESCO Nepal.

Khadka, A. (2006). Literacy in mother tongue: the practice and the outcome. In Rai (2006).

Khadka, A. (2007). Paharis' schooling an understanding from Derridian standpoints. Unpublished M. Phil. Thesis, Faculty of Education, Tribhuvan University, Nepal.

Koirala, B. N., Khadka, A., and Magar, K. J. (2009). Talking with Terai peoples of Nepal. In Press. Kathmandu: Office Support.

Mallikarjun, B. (2002). Multilingual approach towards teaching in Indian schools. In Language in India: Strength for today and bright hope for tomorrow, 2(1). March 2002.

National Language Policy Recommendation Commission (2050 BS). Report of national language policy recommendation commission. Kathmandu: Prayanga Vabhavan.

Rai, N. K. (Ed.) (2006). Nepalese linguistics. Kirtipur, Kathmandu, Nepal: Linguistic Society of Nepal.

Powell, J. (2000). Derrida for beginners. Chennai, India: Orient Longman.

Visci, K. and Vary. A. (2002). Distinctive training methods and evaluation of multilingual multimodal speech training system. Retrieved from www.citeseerx.ist.psu. edu.

Yonjan, A. (2007). Lecture on language issue. M.Phil. Program, Tribhuvan University, Nepal. 